\title{
An, open Morphology of traumatic cataract: does it play a role in final visual outcome?
}

\author{
Mehul A Shah, Shreya M Shah, Shashank B Shah, Chintan G Patel, Utsav A Patel
}

To cite: Shah MA, Shah SM, Shah SB, et al. Morphology of traumatic cataract: does it play a role in final visual outcome? BMJ Open 2011;1: e000060. doi:10.1136/ bmjopen-2011-000060

\section{- Prepublication history for} this paper is available online. To view these files please visit the journal online (http:// bmjopen.bmj.com).

Received 20 January 2011 Accepted 17 June 2011

This final article is available for use under the terms of the Creative Commons Attribution Non-Commercial 2.0 Licence; see http://bmjopen.bmj.com
Drashti Netralaya, Dahod, Gujarat, India

\section{Correspondence to} Dr Mehul A Shah; omtrust@rdiffmail.com

\section{ABSTRACT}

Aim: To study the morphology of traumatic cataract as an important predictor for final visual outcome after treatment of traumatic cataracts.

Setting: Tertiary eye care centre in Dahod at the trijunction of Gujarat, Madhya Pradesh, and Rajasthan states in central western India.

Methods: This was a prospective observational cohort study among all patients presenting at the hospital with traumatic cataracts between January 2003 and December 2009. All information regarding demographic and ocular trauma was collected on a pretested World Eye Trauma Registry form for both the first visit and follow-up. In particular, the authors collected specific information about the morphology of traumatic cataracts; the surgical technique was determined accordingly. Data were entered and analysed with regard to the relationship between type of trauma and resulting injury, results achieved with particular surgical techniques, and the relationship between morphology and final visual outcome.

Outcome measures: Final visual outcome.

Results: Traumatic cataracts of different morphologies showed significant differences in the final visual outcome ( $\chi^{2}$ test, $p=0.014$ ).

Conclusion: The morphology of traumatic cataract plays an important role in the final visual outcome.

\section{INTRODUCTION}

Trauma is a cause of monocular blindness in the developed world, although few studies have addressed the problem of trauma in rural areas. ${ }^{1}$ The aetiology of ocular injury in rural areas is likely to differ from that in urban areas and is worthy of investigation. ${ }^{2-4}$ Any strategy for prevention requires knowledge of the cause of injury, which may enable more appropriate targeting of resources towards preventing such injuries. Eye trauma represents a large, potentially preventable burden on both victims and society as a whole. ${ }^{3}$

Ocular trauma can cause cataracts. ${ }^{1}$ The methods used to evaluate the visual outcome in eyes managed for traumatic cataracts and senile cataracts are similar, ${ }^{5}$ but the damage

\section{ARTICLE SUMMARY}

\section{Article focus}

- Using morphological classification to guide decisions on operative technique; that outcomes after surgery are reported by morphology and surgical technique; and the possible role of morphology is explored.

\section{Key message}

- It is an uncontrolled prospective cohort study.

Strengths and limitations of this study

- Strength: larger database and usage of standard classification method-Birmingham Eye Trauma Terminology System.

- Limitation: included many neglected injury cases.

- Weakness: uncontrolled study, one-third enrolment from outreach limits generalisation of findings, short follow-up; loss of follow-up of 12 patients at various stages of study.

to other ocular tissues owing to trauma may compromise the visual gain in eyes treated surgically for traumatic cataracts. Hence, the success rates may differ between eyes with these two types of cataract.

With the introduction of the Birmingham Eye Trauma Terminology System, the documentation of ocular trauma has been standardised. $^{5}$

Our study was conducted in a city located at the intersection of the borders of three states in India: Gujarat, Madhya Pradesh and Rajasthan. ${ }^{6}$ Qualified ophthalmologists at our institute provide low-cost eye services mainly to the poor belonging to the tribal population of 4.2 million in this area.

There is no standard methodology for classification of traumatic cataract.

\section{PATIENTS AND METHODS}

We obtained approval from the hospital administrators and research committee to conduct this study, and all participants provided written informed consent.

This was a prospective study designed in 2002. All traumatic cataracts in either eye diagnosed and managed between January 


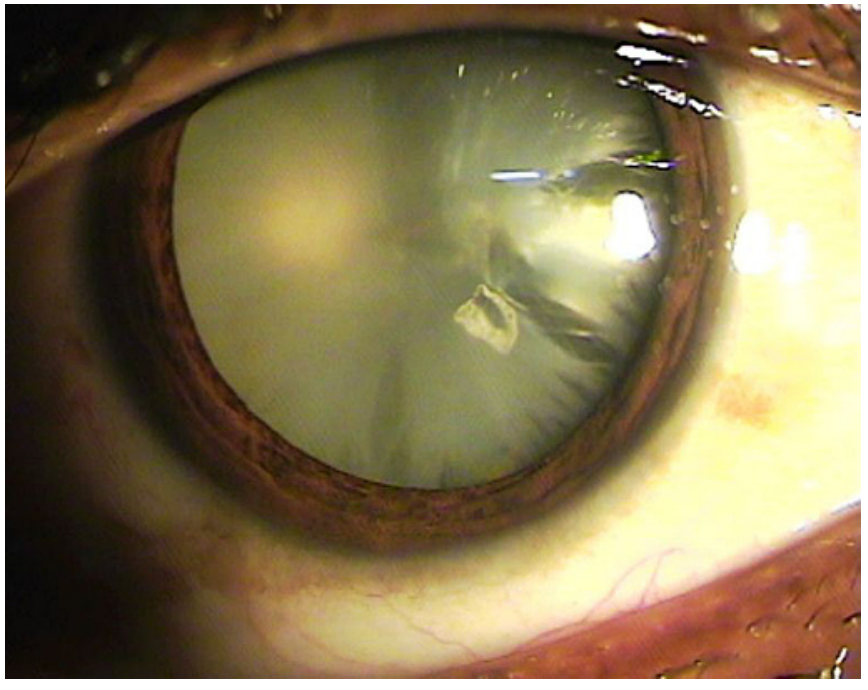

Figure 1 No clear lens matter visible between the capsule and the nucleus, the cataract was defined as a total cataract.

2003 and December 2009 were included in the study, and patients consenting to participate and without other serious body injuries were included. Outreach activities included five different service deliveries mobile diagnostic camps, school screening, mobile vision centre, door-to-door calling on patients and health-worker network.

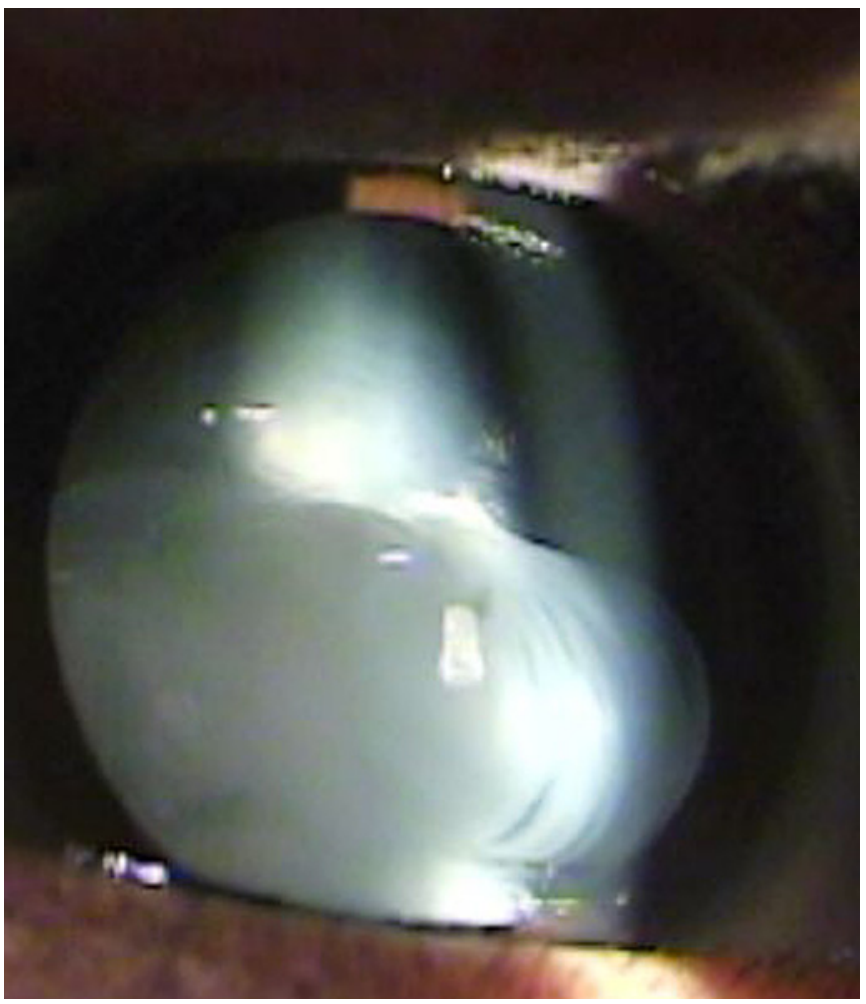

Figure 2 Loose cortical material was found in the anterior chamber together with a ruptured lens capsule, the cataract was defined as a white soft cataract.
For each patient enrolled in our study, we obtained a detailed history, including details of the injury and information on eye treatment and surgery performed to manage past ocular trauma. Data for both the initial and follow-up reports were collected using the online Birmingham Eye Trauma Terminology System format of the International Society of Ocular Trauma. Details of the surgery were also collected using a specified pretested online form.

The cases of traumatic cataract were grouped as those with open- and those with closed-globe injuries. The open-globe injuries were further categorised into those with lacerations and those with rupture. Lacerations of the eyeball were subcategorised into eyes with perforating injuries, penetrating injuries or injuries involving an intraocular foreign body. The closed-globe group was subdivided into lamellar laceration and contusion.

Other demographic details collected included patient entry, residence, activity at the time of injury, object of injury, and previous examinations and treatments. After enrolment, all patients were examined using a standard method. Visual acuity was checked using a Snellen chart, and the anterior segment was examined using a slit lamp.

Based on lenticular opacity, the cataracts were classified as total (figure 1), membranous, in which both capsules fused with scant or no cortical material (figure 2), white soft (figure 3), and rosette types (figure 4). When an ophthalmologist did not observe any clear lens matter between the capsule and nucleus, the cataract was defined as total. When the capsule and

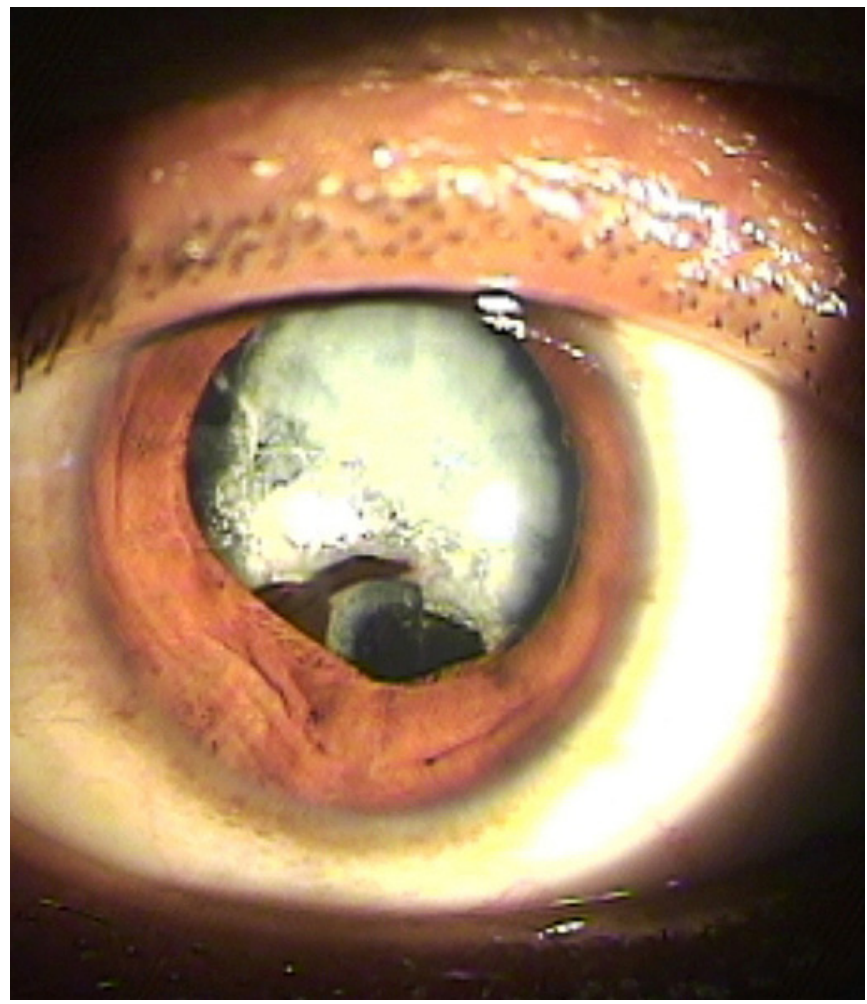

Figure 3 The capsule and organised matter were fused and formed a membrane of varying density, the cataract was defined as a membranous cataract. 


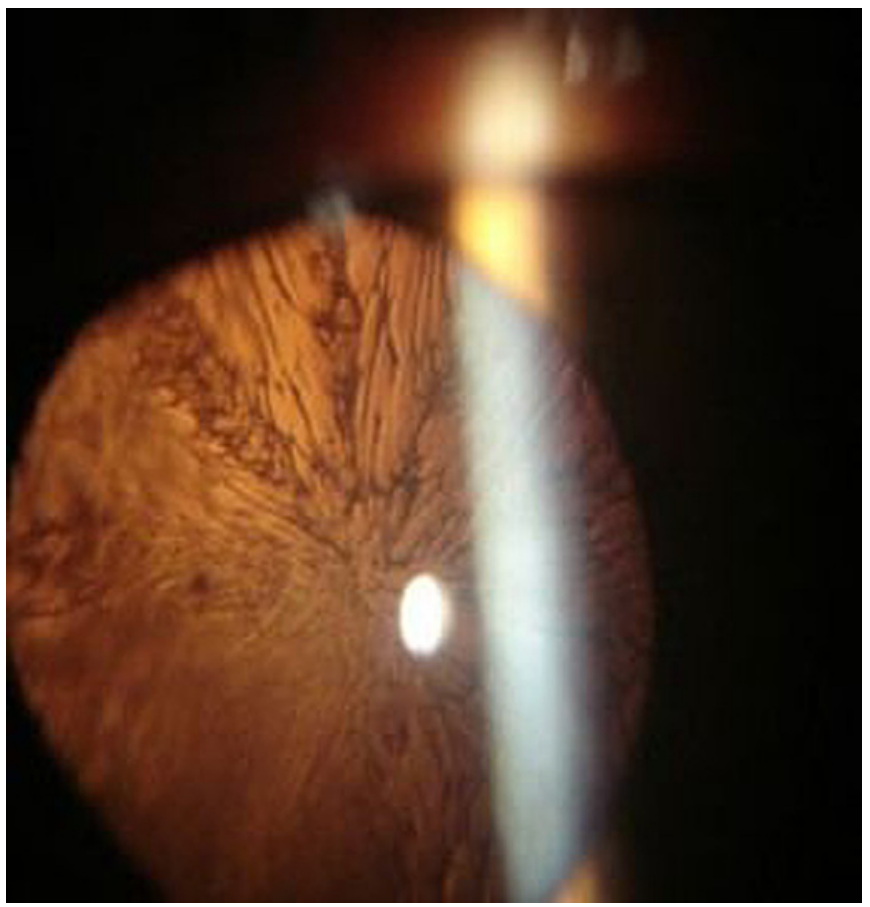

Figure 4 A lens with a rosette pattern of opacity was classified as a rosette type cataract.

organised matter were fused and formed a membrane of varying density, it was defined as a membranous cataract. When loose cortical material was found in the anterior chamber together with a ruptured lens capsule, the cataract was defined as white soft. A lens with a rosette pattern of opacity was classified as a rosette type cataract.

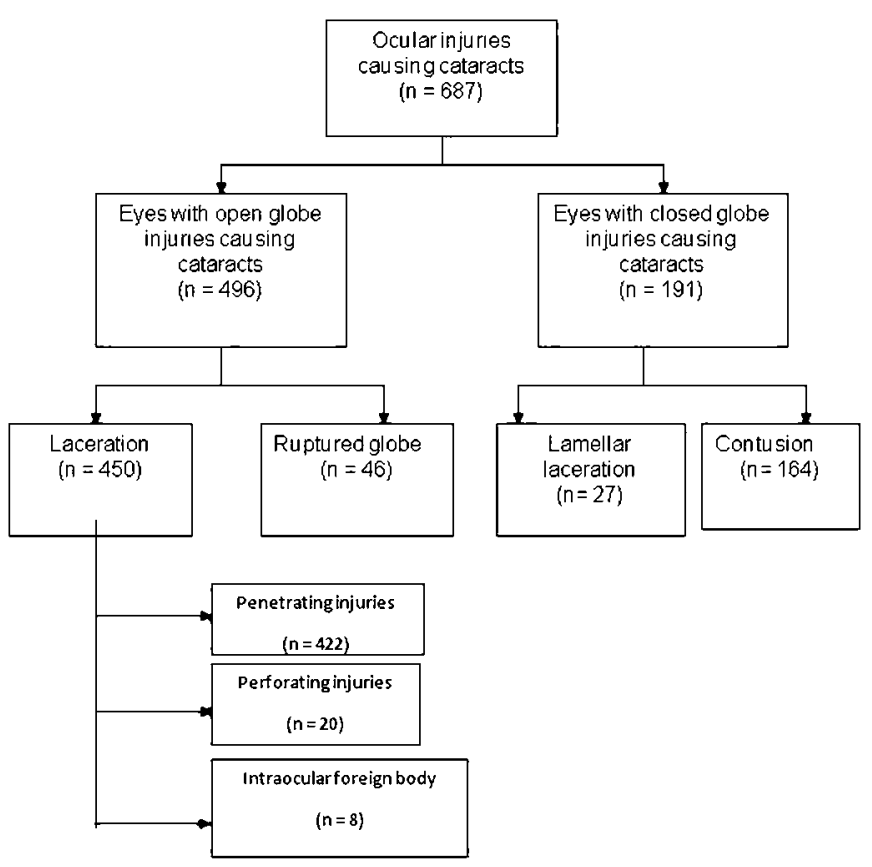

Figure 5 Distribution of cataracts based on the ocular injury, as per the BETTS classification.
For a partially opaque lens, the posterior segment examination was carried out with an indirect ophthalmoscope and $\mathrm{a}+20 \mathrm{D}$ lens. When the optical medium was not clear, a B-scan was performed to evaluate the posterior segment.

The surgical technique was selected according to morphology and the condition of tissues other than the lens. Phacoemulsification was used to treat cataracts with hard, large nuclei. Unimanual or bimanual aspiration was carried out with a lens that had either a white soft or rosette type of cataract. Membranectomy and anterior vitrectomy, via either the anterior or pars plana route, were performed when the cataract was membranous.

In all patients undergoing corneal wound repair, the traumatic cataract was managed in a second procedure. Recurrent inflammation was more prominent in patients who had undergone previous surgery for trauma. ${ }^{7}$ In these cases, the ocular medium may become hazy owing to condensation of the anterior vitreous unless a vitrectomy is performed. Hence, we performed a capsulectomy and vitrectomy via the anterior/pars plana route in adults.

In children younger than 2 years of age, both a lensectomy and vitrectomy via the pars plana route were performed, and the same surgical procedures were used to manage the traumatic cataract, with secondary implants carried out as a separate procedure after the age of 2 years. Lens implantation as part of the primary procedure was avoided in all children younger than 2 years of age. All children were evaluated for amblyopia and were treated with the aid of paediatric ophthalmologists and paediatric optometrists.

All patients with injuries and without infection were treated with topical and systemic corticosteroids and cycloplegics. The duration of medical treatment depended on the degree of inflammation in the anterior and posterior segments of the operated eye. The operated patients were re-examined after $24 \mathrm{~h}, 3$ days, and 1,2 and 6 weeks to enable refractive correction. Follow-up was scheduled for the third day, weekly for 6 weeks, monthly for 3 months and every 3 months for 1 year.

At all follow-up examinations, visual acuity was tested using a Snellen chart. The anterior segment was examined with a slit lamp, and the posterior segment was examined with an indirect ophthalmoscope. Eyes with vision better than 20/60 at the glasses appointment (6 weeks) were defined as having a satisfactory grade of vision.

During the examination, data were entered online using a specified pretested format designed by the International Society of Ocular Trauma (initial and follow-up forms), which was exported to a Microsoft Excel spreadsheet. The data were audited periodically to ensure completeness. We used SPSS V.15 software to analyse the data. The univariate parametric method was used to calculate frequency, percentage, proportion and 95\% CI. We used binominal regression analysis to determine the predictors of postoperative satisfactory 


\begin{tabular}{lc}
$\begin{array}{l}\text { Table } 1 \text { Distribution of different morphologies of traumatic } \\
\text { cataract }\end{array}$ \\
\hline Morphology & $\mathbf{N ~ ( \% )}$ \\
\hline Membranous & $84(12.2)$ \\
Rosette & $8(1.2)$ \\
White soft & $412(60.0)$ \\
Total & $183(26.6)$ \\
Total & $687(100.0)$ \\
\hline
\end{tabular}

vision $(>20 / 60)$. The dependent variable was vision $>20 / 60$ noted at follow-up 6 weeks after cataract surgery. The independent variables were age, gender, residence, time interval between injury and cataract surgery, primary posterior capsulectomy and vitrectomy procedure, and type of ocular injury.

\section{RESULTS}

Our cohort consisted of 687 (72.2) patients with traumatic cataracts (figure 5), including 496 eyes with open-globe ocular injuries and 191 (27.8\%) eyes with closed-globe injuries (figure 5). The patients were $492(71.6 \%)$ males and $195(28.4 \%)$ females. The mean patient age was $27.1 \pm 18.54$ years (range $1-80$ ).

We analysed several demographic factors, including gender $(p=0.340)$, patient entry $(p=0.4)$ and socioeconomic status $(79 \%$ were from lower socio-economic class and residence; $95 \%$ were from rural areas). None of these showed a significant relationship with final visual acuity, according to cross-tabulation and statistical tests. The object causing the injury $(\mathrm{p}=0.3)$ and the activity at the time of the injury $(p=0.3)$ were also not significantly associated with satisfactory final visual acuity All traumatic cataracts were classified according to morphology (tables 1, 2) and were surgically treated using morphology as a guideline (table 3 ).

The number of surgeries required varied significantly with morphology $(\mathrm{p}=0.000)$ (table 4$)$.

Final visual outcome was found to vary according to morphology and surgical technique. White soft cataracts had a better prognosis and achieved significantly higher rates of positive outcome compared with other morphologies $(\mathrm{p}=0.014)$ (table 5$)$.

Lens implants were applied in $82 \%$ of the cases; the details are shown in table 6. There was a significant difference between open and closed injury groups for various age groups $(p=0.000)$ (table 7$)$.

There was no significant difference in final visual outcome in children between open and closed injury groups $(p=0.06)$. A significant difference was found if final visual outcome was compared before and after treatment $(\mathrm{p}=000)$ (table 8$)$. A significant relationship was found between age and final visual outcome $(p=0.000)$, and the final visual outcome is better in the younger age group (table 9). When the time interval between injury and intervention was studied, a significant $(p=0.000)$ effect was found on final visual outcome. ${ }^{6}$

\section{DISCUSSION}

Using a large database, we attempted to systematically classify the morphology of traumatic cataract and to select surgical techniques accordingly.

Vajpayee reported an opening in the posterior capsule with type 1 and 2 openings with a penetrating injury, ${ }^{9}$ whereas we found another membranous type of cataract (12.1\%) suggestive of late reporting, as membranous transformation of the lens with fusion of the anterior and posterior capsules may occur over time. Previous studies have touched on this topic. One study found $52.3 \%$ total cataracts, whereas our results revealed $26.6 \%$ total cataracts. ${ }^{10}$ We were able to perform intraocular lens implants in $82.1 \%$ of the cases. Krishnamachary et $a l^{10}$ reported implants in $65.5 \%$ of cases, Churchill et $a l^{11}$ reported implants in $46.8 \%$, and Fyodorov et al reported Sputnik implants in all cases. ${ }^{7} 810$

Fyodorov reported surgical techniques according to pathology and degree of lens absorption but did not systematically classify similar factors taken into account in our study. 8

These differences in findings may reflect the fact that of the 687 patients in our study, 30\% came from outreach activities and did not attend the treatment facilities on their own. Therefore, the time period between ocular injury and reporting ranged widely, and morphology was also influenced by this interval.

We share our experience with the treatment strategy for different morphological verities for traumatic cataracts. As an uncontrolled study, it cannot provide firm evidence that this strategy led to improved outcomes, but it does provide a large dataset to help develop further research questions.

Table 2 Morphology of traumatic cataract according to type of injury

\begin{tabular}{lccc}
\hline BETTS category & Closed globe & Open globe & Total \\
Morphology & N (\%) & N (\%) & N (\%) \\
\hline Membranous & $20(2.9)$ & $64(9.3)$ & $84(12.2)$ \\
Rosette & $3(0.4)$ & $5(0.7)$ & $8(1.1)$ \\
White soft with ruptured anterior & $83(12.1)$ & $329(47.9)$ & $412(59.9)$ \\
capsule & & & \\
Total & $85(12.4)$ & $98(14.3)$ & $183(26.6)$ \\
Total & $191(27.8)$ & $496(72.2)$ & $687(100)$ \\
\hline
\end{tabular}


Table 3 Surgical techniques used according to the morphology of cataract

\begin{tabular}{|c|c|c|c|c|c|}
\hline \multirow[b]{2}{*}{ Surgical technique } & \multicolumn{4}{|l|}{ Morphology } & \multirow[b]{2}{*}{$\begin{array}{l}\text { Total } \\
\text { N (\%) }\end{array}$} \\
\hline & $\begin{array}{l}\text { Membranous } \\
\text { N (\%) }\end{array}$ & $\begin{array}{l}\text { Rosette } \\
\text { N (\%) }\end{array}$ & $\begin{array}{l}\text { White soft } \\
\text { N (\%) }\end{array}$ & $\begin{array}{l}\text { Total } \\
\text { N (\%) }\end{array}$ & \\
\hline Aspiration & $7(1)$ & $5(0.7)$ & $316(45.9)$ & $19(2.7)$ & $347(50.5)$ \\
\hline Lensectomy+vitrectomy & $46(6.7)$ & $0(0)$ & $60(8.7)$ & $20(2.9)$ & $126(18.3)$ \\
\hline $\begin{array}{l}\text { Phaco/small incision cataract } \\
\text { surgery }\end{array}$ & $3(0.4)$ & $2(0.3)$ & $17(2.4)$ & $108(15.7)$ & 130 (18.9) \\
\hline Delivery+vitrectomy & $28(4)$ & $0(0)$ & $20(2.9)$ & $36(5.2)$ & $84(12.2)$ \\
\hline Total & $83(12.1)$ & $7(1)$ & $412(59.9)$ & $183(26.6)$ & $687(100)$ \\
\hline
\end{tabular}

Table 4 Morphology of cataract in relation to the number of surgical procedures

\begin{tabular}{|c|c|c|c|c|c|}
\hline \multirow[b]{2}{*}{$\mathbf{N}$} & \multicolumn{4}{|l|}{ Morphology } & \multirow[b]{2}{*}{$\begin{array}{l}\text { Total } \\
\text { N (\%) } \\
\end{array}$} \\
\hline & $\begin{array}{l}\text { Membranous } \\
\text { N (\%) }\end{array}$ & $\begin{array}{l}\text { Rosette } \\
\text { N (\%) }\end{array}$ & $\begin{array}{l}\text { White soft } \\
\text { N (\%) }\end{array}$ & $\begin{array}{l}\text { Total } \\
\text { N (\%) } \\
\end{array}$ & \\
\hline 1.00 & $70(10.1)$ & $6(0.8)$ & $349(50.8)$ & $159(23.1)$ & $584(85.0)$ \\
\hline 2.00 & 12 (1.7) & $2(0.2)$ & $58(8.4)$ & $22(3.2)$ & $94(13.7)$ \\
\hline 3.00 & $2(0.3)$ & $0(0)$ & $5(0.7)$ & $2(0.2)$ & $9(1.3)$ \\
\hline Total & $84(12.2)$ & $8(1)$ & $412(59.9)$ & $183(26.6)$ & 687 (100) \\
\hline
\end{tabular}

Table 5 Final visual outcome in relation to the morphology of cataract

\begin{tabular}{|c|c|c|c|c|c|}
\hline \multirow[b]{2}{*}{ Final visual outcome } & \multicolumn{4}{|l|}{ Morphology } & \multirow[b]{2}{*}{$\begin{array}{l}\text { Total } \\
\text { N (\%) }\end{array}$} \\
\hline & $\begin{array}{l}\text { Membranous } \\
\text { N (\%) }\end{array}$ & $\begin{array}{l}\text { Rosette } \\
\text { N (\%) }\end{array}$ & $\begin{array}{l}\text { White soft } \\
\text { N (\%) }\end{array}$ & $\begin{array}{l}\text { Total } \\
\text { N (\%) }\end{array}$ & \\
\hline Uncooperative & $3(0.4)$ & $0(0)$ & $11(1.6)$ & $5(0.7)$ & $19(2.7)$ \\
\hline$<1 / 60$ & $24(3.5)$ & $2(0.3)$ & 89 (12.9) & $58(8.4)$ & $173(25.1)$ \\
\hline $1 / 60$ to $3 / 60$ & $12(1.7)$ & $0(0)$ & 27 (3.9) & $19(2.7)$ & $58(8.4)$ \\
\hline $20 / 200$ to $20 / 120$ & $7(1.0)$ & $1(0.1)$ & $33(4.8)$ & $25(3.6)$ & $66(9.6)$ \\
\hline $20 / 80$ to $20 / 60$ & $21(3.0)$ & $1(0.1)$ & $91(13.2)$ & $34(4.9)$ & $147(21.4)$ \\
\hline $20 / 40$ to $20 / 20$ & $17(2.5)$ & $4(0.5)$ & $161(23.4)$ & $42(6.1)$ & 224 (32.6) \\
\hline Total & $83(12.1)$ & $7(1.0)$ & 412 (59.9) & $183(26.6)$ & $687(100)$ \\
\hline
\end{tabular}

Table 6 Lens implant in relation to the morphology of traumatic cataract

\begin{tabular}{lccc}
\hline Morphology & $\begin{array}{l}\text { No implant } \\
\text { N (\%) }\end{array}$ & $\begin{array}{l}\text { Implant } \\
\text { N (\%) }\end{array}$ & $\begin{array}{l}\text { Total } \\
\text { N (\%) }\end{array}$ \\
\hline Membranous & $17(2.5)$ & $67(9.8)$ & $84(12.2)$ \\
Rosette & $2(0.3)$ & $6(0.9)$ & $8(1.2)$ \\
White soft & $58(8.4)$ & $354(51.5)$ & $412(60.0)$ \\
Total & $46(6.7)$ & $137(19.9)$ & $183(26.6)$ \\
Total & $123(17.9)$ & $564(82.1)$ & $687(100)$ \\
\hline$\chi^{2}$ test, $\mathrm{p}=0.004$. & & &
\end{tabular}

Table 7 Comparison of open and closed globe injuries in children

\begin{tabular}{lcll}
\hline Category & $\begin{array}{l}\text { Closed globe } \\
\mathbf{N}(\%)\end{array}$ & $\begin{array}{l}\text { Open globe } \\
\mathbf{N}(\%)\end{array}$ & $\begin{array}{l}\text { Total } \\
\mathbf{N}(\%)\end{array}$ \\
\hline Paediatric & $54(7.7)$ & $253(36.8)$ & $307(44.7)$ \\
Adult & $137(19.9)$ & $243(35.3)$ & $380(55.3)$ \\
Total & $191(27.8)$ & $496(72.1)$ & $687(100)$ \\
\hline$\chi^{2}$ test, $\mathrm{p}=0.000$. & &
\end{tabular}


Table 8 Comparative visual acuity before and after treatment

\begin{tabular}{|c|c|c|c|c|c|c|c|c|c|c|c|c|c|c|}
\hline \multirow{3}{*}{$\frac{\text { Preop vision }}{\text { Uncooperative }}$} & \multicolumn{12}{|c|}{ Post-treatment vision } & \multirow{2}{*}{\multicolumn{2}{|c|}{ Total }} \\
\hline & \multicolumn{2}{|c|}{ Uncooperative } & \multicolumn{2}{|c|}{$<1 / 60$} & \multicolumn{2}{|c|}{$\begin{array}{l}1 / 60 \text { to } \\
3 / 60\end{array}$} & \multicolumn{2}{|c|}{$\begin{array}{l}20 / 200 \\
\text { to } 20 / 120\end{array}$} & \multicolumn{2}{|c|}{$\begin{array}{l}20 / 80 \text { to } \\
20 / 60\end{array}$} & \multicolumn{2}{|c|}{$\begin{array}{l}20 / 40 \text { to } \\
20 / 20\end{array}$} & & \\
\hline & 7 & 1.01 & 0 & 0 & 0 & 0 & 0 & 0 & 1 & 0.14 & 2 & 0.29 & 10 & 1.45 \\
\hline$<1 / 60$ & 10 & 1.45 & 164 & 23.87 & 53 & 7.71 & 54 & 7.86 & 110 & 16.01 & 191 & 27.80 & 582 & 84.71 \\
\hline $1 / 60$ to $3 / 60$ & 0 & 0 & 4 & 0.58 & 3 & 0.43 & 8 & 1.16 & 21 & 3.05 & 10 & 1.45 & 46 & 6.69 \\
\hline $6 / 60$ to $6 / 36$ & 0 & 0 & 0 & 0 & 0 & 0 & 1 & 0.14 & 7 & 1.01 & 12 & 1.74 & 20 & 2.91 \\
\hline $6 / 24$ to $6 / 18$ & 0 & 0 & 3 & 0.43 & 0 & 0 & 1 & 0.14 & 6 & 0.87 & 7 & 1.01 & 17 & 2.47 \\
\hline $6 / 12$ to $6 / 6$ & 0 & 0 & 0 & 0 & 0 & 0 & 0 & 0 & 0 & 0 & 1 & 0.14 & 1 & 0.14 \\
\hline Total & 17 & 2.47 & 171 & 24.89 & 55 & 8.00 & 64 & 9.31 & 145 & 21.10 & 223 & 32.45 & 675 & 98.5 \\
\hline
\end{tabular}

$\chi^{2}$ test, $p=0.000$.

\begin{tabular}{|c|c|c|c|c|c|c|c|}
\hline Age & $\begin{array}{l}\text { Uncooperative } \\
\text { n (\%) }\end{array}$ & $\begin{array}{l}<1 / 60 \\
\mathrm{n}(\%)\end{array}$ & $\begin{array}{l}1 / 60 \text { to } 3 / 60 \\
\text { n (\%) }\end{array}$ & $\begin{array}{l}20 / 200 \text { to } 20 / 120 \\
\text { n (\%) }\end{array}$ & $\begin{array}{l}20 / 80 \text { to } 20 / 60 \\
\text { n (\%) }\end{array}$ & $\begin{array}{l}20 / 40 \text { to } 20 / 20 \\
\text { n (\%) }\end{array}$ & $\begin{array}{l}\text { Total } \\
\text { n (\%) }\end{array}$ \\
\hline $0-10$ & $9(1.31)$ & 46 (6.69) & $15(2.18)$ & $12(1.74)$ & 37 (5.38) & $34(4.94)$ & $153(22.27)$ \\
\hline $11-20$ & $2(0.29)$ & 30 (4.36) & $14(2.03)$ & $17(2.47)$ & $33(4.80)$ & 87 (12.66) & 183 (26.63) \\
\hline $21-30$ & $2(0.29)$ & $19(2.76)$ & $8(1.16)$ & $6(0.87)$ & $12(1.74)$ & $42(6.11)$ & 89 (12.95) \\
\hline $31-40$ & $1(0.14)$ & 23 (3.35) & $5(0.73)$ & 7 (1.01) & 16 (2.32) & 25 (3.63) & 77 (11.2) \\
\hline $41-50$ & $3(0.43)$ & 23 (3.35) & $6(0.87)$ & $12(1.74)$ & 28 (4.07) & 22 (3.20) & 94 (13.68) \\
\hline $51-60$ & $0(0.0)$ & $21(3.00)$ & 7 (1.01) & $6(0.87)$ & $8(1.16)$ & $11(1.60)$ & $53(7.71)$ \\
\hline $61-70$ & $0(0.0)$ & $8(1.16)$ & $0(0)$ & $2(0.29)$ & $10(1.45)$ & $2(0.29)$ & $22(3.20)$ \\
\hline $71-80$ & $0(0.0)$ & $1(0.14)$ & $0(0)$ & $2(0.29)$ & $1(0.14)$ & $0(0)$ & $4(0.58)$ \\
\hline Total & $17(2.47)$ & $173(25.18)$ & $55(8.00)$ & $64(9.31)$ & $146(21.25)$ & $223(32.45)$ & 675 (98.5) \\
\hline
\end{tabular}

Morphology of traumatic cataract appeared to be associated with final visual outcome following surgical treatment.

Acknowledgements We thank D Netralaya for allowing us to conduct this study.

Competing interests None.

Patient consent Obtained.

Ethics approval Hospital ethical committee.

Contributors MAS: concept design study, surgeon, writing. SMS:

administrative support, writing, data analyses. SBS: data collection, language editing. CGP: data collection proofreading and editing. UAP: data collection and editing.

Provenance and peer review Not commissioned; externally peer reviewed. Data sharing statement Data available on request.

\section{REFERENCES}

1. Khatry SK, Lewis AE, Schein OD, et al. The epidemiology of ocular trauma in rural Nepal. Br J Ophthalmol 2004;88:456-60.
2. Abraham DI, Vitale SI, West SI, et al. Epidemiology of eye injuries in rural Tanzania. Ophthalmic Epidemiol.1999;6:85-94.

3. Alfaro DV 3rd, Jablon EP, Rodriguez Fontal M, et al. Fishing-related ocular trauma. Am J Ophthalmol 2005;139:488-92.

4. Shah M, Shah S, Khandekar R. Ocular injuries and visual status before and after Their management in the tribal areas of Western India: a historical cohort study. Grafes Arch Clin Exp Ophthalmol 2008:246:191-7.

5. Kuhn F, Morris R, Witherspoon CD, et al. The Birmingham Eye Trauma Terminology system (BETT). J Fr Ophtalmol 2004:27:206-10.

6. Shah MA, Shah SM, Shah SB, et al. Effect of interval between time of injury and timing of intervention on final visual outcome in cases of traumatic cataract. Eur J Ophthalmol. Published Online First: 24 March 2011. doi:10.5301/EJO.2011.6482. pii: 338AC21D-E9FB42DF-9C28-6FDE61928C9D.

7. Thylefors B, Chylack LT Jr, Konyama K, et al. A simplified cataract grading system. Ophthalmic Epidemiol 2002;9:83-95.

8. Fyodorov SN, Egorova EV, Zubareva LN. 1004 cases of traumatic cataract surgery with implantation of an intraocular lens. J Am Intraocul Implant Soc 1981;7:147-53.

9. Vajpayee RB, Sharma N, Dada T, et al. Management of posterior capsule tears. Surv Ophthalmol 2001;45:473-88.

10. Krishnamachary M, Rathi V, Gupta S. Management of traumatic cataract in children. J Cataract Refract Surg 1997;23:681-7.

11. Churchill AJ, Noble BA, Etchells DE, et al. Factors affecting visual outcome in children following uniocular traumatic cataract. Eye (Lond) 1995;9:285-91. 